\title{
Shadow Economy and National Culture: A Spatial Approach*
}

\author{
GLORIA ALARCÓN-GARCÍA** \\ JOSÉ DANIEL BUENDÍA AZORÍN *** \\ MARÍA DEL MAR SÁNCHEZ DE LA VEGA**** \\ Universidad de Murcia
}

Received: September, 2018

Accepted: March, 2019

\begin{abstract}
This paper seeks to contribute to the empirical evidence on existing estimations of the factors participating in shadow economy. The estimations correspond to the period 1999-2015, with a sample of 82 countries.

The paper examines the effect of the Hofstede cultural variables, along with other socioeconomic factors on the shadow economy, and incorporates the spatial variable as an additional explanatory variable. The estimation carried out as a novelty uses a panel model that incorporates the spatial filter technique. Our study confirms that national culture and how developed a country is are significant factors in explaining the different levels of shadow economies.
\end{abstract}

Keywords: Hofstede theory, shadow economy, fiscal evasion, tax compliance, spatial dependence.

JEL Classification: H2, H26, O17, O5.

\section{Introduction}

The shadow economy is a subject of considerable interest, being an important policy goal in OECD countries to reduce it, understanding its mechanisms and determinants has great importance. A large literature on several aspects on the shadow economy already exists and this work aims at contributing to this issue by analyzing the influence of the Hofstede's variables with a spatial econometric approach.

\footnotetext{
* We would like to thank two anonymous referees for their comments and useful suggestions that have improved the actual version of this article.

** ORCID ID: 0000-0003-1177-6026.

*** ORCID ID: 0000-0001-9302-7971.

**** ORCID ID: 0000-0002-8647-6215.
} 
Hofstede's theory is based on the fact that each person carries within himself the patterns of thought, feeling and potential action that are learned throughout his life (Hofstede, 1980). These learned patterns differ according to the nation of origin and are part of the components of attitudes to different situations of people. Culture and differences between countries play a preponderant role in various areas of research. Hofstede's theory (Franke et al. 1991) has been used to evaluate differences in economic performance at the national level. The empirical analysis showed the potential of cultural determinants to explain economic phenomena and linked culture and economy.

One of the novelties of our paper is that it analyses spatial effects, since the presence of spatial autocorrelation in the variables considered is a fundamental aspect that needs to be taken into account. The most common techniques for analyzing data presenting autocorrelation use models that directly specify a spatial structure, and of these the most frequent are spatial autoregressive models. Another approach, which has not hitherto been used to analyze shadow economy, is Griffith's spatial filtering technique $(1996,2000)$, which is what we do in this paper.

The recent paper by Goel and Saunoris (2014) represents a pioneer piece of work in the study of spatial effects on shadow economy, although the authors do not consider the Hofstede variables.

Our findings confirm that the geographical distribution of shadow economy reveals a pattern in which there is a certain trend to grouping countries according to a spatial dependence pattern in which countries with similar levels of shadow economy are grouped together. Thus, countries with high levels of shadow economy have neighboring countries with similarly high levels, and the same holds for this with medium and low levels, respectively.

We would also point out that our paper extends the study by Tsakumis et al. (2007) that analyzes the dependence of shadow economy on the Hofstede variables in several ways. First, our sample comprises 82 countries, compared to the 50 analyzed in the above paper. Second, along with the Hofstede variables we analyze a broad set of socioeconomic variables that may be determining in shadow economy. Third, we consider a very recent period of time, from 1999 to 2015. Finally, and noteworthily, our study incorporates spatial effects -a fundamental aspect, and one not addressed by Tsakumis et al. (2007). Our findings indicate the importance of the spatial adjustment, for the distribution of the shadow economy values exhibits a strong spatial correlation. Estimated outcomes show some notable differences regarding those obtained by these authors. Robustness of outcomes was checked by estimating different regressions with alternative specifications.

In brief, the paper contributes to the existing literature in several ways. We analyze spatial effects by spatial filtering, which has not hitherto been used to study shadow economy; we use a much wider sample than the one used in other similar studies and examine other variables, among them countries' legal systems, in conjunction with national culture; we estimate three alternative models; and concerning the relationship between the four dimensions of national culture analyzed, we find that only individualism, uncertainty avoidance and masculinity are significant determinants of shadow economy. 
In the next section we outline some fundamental aspects of shadow economy and we describe the Hofstede theory and its incorporation within our analysis. Section 3 provides a brief definition of spatial autocorrelation and the spatial filtering. Section 4 describes the methodology and data used, and the principal results are given in Section 5. Section 6 offers the main conclusions.

\section{Theoretical background}

\subsection{Shadow economy}

Shadow economy can be defined as all activities that should form part of the part of the gross domestic product (GDP) and are not officially registered, with the exception of those not included in the calculation of the GDP, for example household chores (Frey and Schneider, 2015; Schneider and Medina, 2017), and illegal actions with criminal features like theft, drug trafficking, etc. (Torgler et al., 2010). Shadow economy can be a response to defensive or aggressive conducts on the part of economic agents (De Juan, 1995). If the taxpayers are not satisfied with the public services they receive in exchange for their taxation, they will seek to redress the balance by "fleeing" to shadow economy (Frey and Schneider, 2015). A substantial increase in shadow economy may lead to significant decrease in tax income and, hence, to fewer and worse social goods and services (Frey and Schneider, 2015; Torgler et $a l ., 2010)$. Moreover, shadow economy raises issues of equity and efficiency (Arrazola and Mauleón, 2011); it produces unfair competition among businesses, tax evasion, the disappearance of regulations, poor working conditions, few or no safety measures in the workplace, and fewer National Health contributions. It also has important long-term consequences, such as payments into pension schemes or the right to receive all types of public services (Sardá, 2014). Shadow economy is a phenomenon of homo economicus and individualism and it undermines the foundations of society since self interest and private profitability are the sole criteria, and solidarity is pushed aside (Frey and Schneider, 2015). Shadow economy is, on the basis of the above, closely linked to ethics and tax morale, and these types of activities are in turn closely linked to voluntary tax payment (Frey and Schneider, 2015). It is, therefore, a problem of morality and fiscal awareness. So, when a society or an individual does not see certain attitudes related to shadow economy (e.g., not paying VAT or benefiting from tax advantages one is not entitled to) as deserving condemnation, then that society or individual is opting for a high level of shadow economy along with all its implications. In contrast, when a society or individual does perceive that these attitudes and behaviors harm the whole group and are to be condemned, then the problem of shadow economy begins to wane (Sardá, 2014).

Frey and Schneider (2015) claim that countries with a smaller public sector -Japan, USA and Switzerland, among others- and with higher tax morals -USA and Switzerland- have less shadow economy. Also, greater centralization correlates positively with an increase in shadow economy. This indicates that local government autonomy plays an important role in the size of the shadow economy (Torgler et al., 2010). The same authors report a negative 
relation between local government autonomy and the amount of shadow economy. Added to the above, countries fiscal morals show a clear tendency towards larger shadow economies, so there should be a negative and significant correlation between tax morale and the size of the shadow economy (Torgler, 2001, 2005; Torgler and Schneider, 2009). This is the line taken in Alarcón et al. (2016), who, as a novelty, incorporated a variable that referred to building. According to the Spanish Ministry for Economy and Tax, a large part of fraud and shadow economy is related to operations by construction and real estate businesses, so it is to be expected that the greater the amount of shadow economy there is in a region, the less reproachable the tax fraud (Alarcón et al., 2016).

The findings of the above paper allow us to state that rejection of fraud is negatively correlated with the weight of the construction sector, that this has a strong impact tax morale, and hence, the greater the presence of the construction sector in an area, the lesser the rejection of tax fraud. Individuals who accept shadow economy also justify tax evasion more (Molero and Pujol, 2012). However, despite the existence of shadow economy, it is possible to encourage adherence to the official economy by improving the efficiency of public services, lowering the tax burden, National Health contributions, income tax, and by increasing civism; although these measures would in any case only be effective in the long term (Frey and Schneider, 2015).

\subsection{National cultural dimensions}

Hofstede's theory is based on a research project framed in human resources that investigated the differences between cultures among employees of International Business Machines, IBM. Although the study was initially undertaken in human resources, subsequent applications have not been limited to this area (De Mooij, 2004).

Thus, the studies derived from this research have identified evidence of differences and similarities between the patterns of the culture of countries, initially in 4 dimensions.

The dimensions derived from Hofstede's (1980) research are power distance, which describes how the less powerful members of a society accept and expect an inequity of power; individualism, which is the extent to which people feel independent as opposed to being interdependent as members of larger groups; masculinity, which measures the way in which the use of force is endorsed socially; uncertainty avoidance, which relates the tolerance of a society according to its uncertainty and ambiguity. The last two dimensions have been developed by various subsequent studies that have incorporated long term orientation, which deals with change and attitudes, and, finally, indulgence, which examines the importance of happiness and the control of life.

Hofstede's work was revolutionary since it went from a descriptive theory to an ordinal measurement of the countries for each of these dimensions, based on the questionnaires administered between 1968 and 1972 to 88,000 national employees in more than 40 IBM subsidiaries abroad. It is important to mention Hofstede's definition of "culture", which is 
"collective mind programming that distinguishes members of one group or category of people from another" (Hofstede, 1991).

This theory is based on the fact that each person carries within himself the patterns of thought, feeling and potential action that were learned throughout his life (Hofstede, 1980). Such patterns learned differ according to the nation of origin, which, in turn, are part of the components of attitudes to different situations of people. Culture and differences between countries play a preponderant role in various areas of research. Thus, we find a vast amount of literature that uses the Hofstede dimensions, among which are marketing, advertising, planning and, in a more limited way, decision making, education and other economic aspects (De Mooij and Hofstede, 2002; Hofstede, 1993, 1994; Hermeking, 2005 and De Mooij and Hofstede, 2010).

On the one hand, Hofstede (1993) used his dimensions to question US management theories, stating that theories that may work for this country can differ from those that would work for others given their cultural context differences. In his study "Cultural Dimensions in Management and Planning" he makes a thorough review of the implications in management and planning theories and how they correlate with their cultural dimensions (Hofstede, 1984). Contributing valuable information to the literature of these areas through the incorporation of cultural determinants, Steenkamp et al. (1999) find that cultural dimensions play a key role in consumer preference for innovation. The study reveals a positive relationship with individualism and masculinity, while reflecting a negative relationship with uncertainty avoidance.

In marketing and advertising areas the dimension masculinity had been used to explain the difference in the representation of women and men in advertising on the web. The results confirm the potential of the Hofstede framework in marketing and advertising research by examining gender-related advertising types that might be appropriate in a specific culture (An and Kim, 2007).

Kogut and Singh (1988) analyzed the effect of the national culture in the choice of the way of entry of multinational companies, using the dimension of uncertainty avoidance and an index composed of all the dimensions with respect to the United States, called cultural distance. The results of the study reveal a positive relationship between the mentioned variables and the probability of choosing the joint venture and greenfield as the option of entry. The study suggests that when economic choice between countries is compared, cultural characteristics are likely to have profound implications.

One of the main attractions of the dimensions of Hofstede, and its use as independent variables, is the independence of values between them. Only power distance and individualism are interdependent, and both are correlated with the country's per capita GDP. However, once this aspect is controlled, the correlation disappears.

Cultural differences have helped to understand which strategies or theories are most convenient according to the country under analysis and the parameter analyzed. The Hofstede model allows countries to be grouped according to the type of cultural effect that is expected of them given their indices, and has become a fundamental tool for the choice of strategies 
and theories in areas such as marketing, retailing and web design (De Mooij and Hofstede, 2002; Hofstede, 1993; Hermeking, 2005 and De Mooij, M. and Hofstede, 2010).

The Hofstede model is not limited to the areas mentioned above. With fewer studies, but nevertheless important results, Hofstede's theory has also been used for the analysis of the behavior of decisions and the interactions between distinct roles, such as teacher-student. Smith and Hume, (2005) relates the dimensions of individualism and power distance with questionable decisions of tax professionals from different countries. In their work, he finds that professionals from countries with a lower individuality index, that is, collectives, will be more in agreement with decisions of questionable behavior. Hofstede (1986) analyzes the cultural differences between teaching and learning when students and teachers do not come from the same country and exhibit differences in the dimensions of Hofstede. The results are of significant importance in the field of education, mainly for schools that have a great cultural diversity as is the case in the United States.

In addition to this, Hofstede's theory (Franke et al., 1991) has been used to evaluate differences in economic performance at the national level. This empirical analysis showed the potential of cultural determinants in explaining economic phenomena and it linked culture and economy. Their study suggests that values fostered in the families, organizations and political life of a nation are reflected in their economic statistics. Johnson and Lenartowicz (1998) studied culture, freedom, and economic growth and found evidence of a strong positive association between economic freedom and individualism and a negative one between uncertainty avoidance and economic freedom. Finally, the relationship of cultural dimensions has also been linked to tax evasion. Tsakumis et al. (2007) analyzed the role of the national culture in explaining the countries' tax evasion behavior. These authors use the estimations of Schneider (2004) of the shadow economy as a proxy for tax evasion. Specifically, their dependent variable, tax evasion, is the country's shadow economy as a percentage of its official GDP. They consider that the larger the value of percentage of shadow economy, the greater the extent of tax evasion is in a country. The study finds that tax evasion is greater in countries with greater power distance and uncertainty avoidance, and less individualism and masculinity.

\section{Spatial autocorrelation. Semiparametric filtering of spatial autocorrelation: the eigenvector approach}

A variable exhibits spatial autocorrelation when its value somewhere in space is related to its value somewhere else. The spatial correlation modelling is made through the matrix of weights or connectivity matrix $(W)$. In this work, we use a binary matrix of zeros and ones, $W=\left(w_{i j}\right)_{n}$, obtained by using the queen criterion of contiguity ${ }^{1}$.

To test for the existence of spatial autocorrelation, we use the Moran's statistic. The test agrees that the shadow economy exhibits spatial autocorrelation.

The most used techniques in analyzing data with spatial autocorrelation employ models that directly specify a spatial structure, with spatial autoregressive models being the most 
usual $^{2}$. An alternative approach is the Griffith spatial filtering (1996, 2000), which is the one we use here ${ }^{3}$. This procedure decomposes the variable studied according to a systemic or non spatial component which is a linear combination of the explanatory variables observed and a spatial component formed by a linear combination of synthetic variables that represent the spatial structure of the dataset. These components can be incorporated into an ordinary least squares (OLS) framework or to generalized lineal models (GLM). In Griffith (1996, 2000) consideration is given to the eigenvectors of the $M W M$ matrix, where $W$ is the matrix of weights, $M=I-1\left(1^{t} 1\right) 1^{t}$, I is the identity matrix of order $n$, and a vector of order $n \times 1$, whose elements are all equal to 1 . The technique they develop is to insert these eigenvectors as regressors in order to construct a linear regression model in which errors do not present spatial dependence and, hence OLS estimation techniques can be used.

In a nutshell, the spatial filtering technique used in this study requires:

1) Computation of eigenvectors of the transformed contiguity matrix $M W M$. Where $M$ and the weights matrix $W$ are defined above, with $n=82$.

2) Selection of a subset of such vectors to be added to the right hand side of the model to reduce residual autocorrelation to below a specified alpha value. ${ }^{4}$ The set obtained comprises 19 eigenvectors, denoted by

$$
e_{1}, e_{2}, e_{3}, e_{4}, e_{5}, e_{6}, e_{7}, e_{8}, e_{10}, e_{11}, e_{12}, e_{13}, e_{14}, e_{15}, e_{16}, e_{17}, e_{18}, e_{19}
$$

3) Eliminate from the set obtained in the previous step the elements that are not significant as explanatory variables of shadow economy for each year, $t$, of the period considered. In doing so, we leave a set of significant eigenvectors for each year, $S_{t}$. This process is carried out by means of a stepwise regression analysis for each cross section. The eigenvectors obtained are given in Table 1.

4) Determine the eigenvectors found in step 3 that are common to all the years. Table 1 presents the common eigenvectors obtained. This set of eigenvectors constitutes the spatial filter for the shadow economy for the entire time period considered.

5) Estimate the panel model in which the dependent variable is shadow economy and the explanatory variables are the socioeconomic variables considered and the eigenvectors obtained in step 4 .

Table 1

SELECTED EIGENVECTORS, 1999-2015: YEAR-SPECIFIC AND COMMON

\begin{tabular}{cccc}
\hline Year & \#of eigenvectors & Year-specific eigenvectors & Common eigenvectors \\
\hline 1999 & 12 & $e_{7}, e_{10}, e_{15}$ & \\
2000 & 12 & $e_{7}, e_{10}, e_{15}$ & $e_{1}, e_{2}, e_{4}, e_{5}, e_{6}, e_{9}, e_{11}, e_{12}, e_{18}$ \\
2001 & 11 & $e_{7}, e_{10}$ & \\
2002 & 11 & $e_{7}, e_{10}$ &
\end{tabular}


(Continued)

\begin{tabular}{cccc}
\hline Year & \#of eigenvectors & Year-specific eigenvectors & Common eigenvectors \\
\hline 2003 & 13 & $e_{7}, e_{8}, e_{10}, e_{15}$ & \\
2004 & 13 & $e_{7}, e_{8}, e_{10}, e_{15}$ & \\
2005 & 13 & $e_{7}, e_{8}, e_{10}, e_{15}$ & \\
2006 & 12 & $e_{7}, e_{10}, e_{15}$ & \\
2007 & 13 & $e_{7}, e_{8}, e_{10}, e_{15}$ & \\
2008 & 14 & $e_{7}, e_{8}, e_{10}, e_{14}, e_{15}$ & \\
2009 & 14 & $e_{7}, e_{8}, e_{10}, e_{14}, e_{15}$ & \\
2010 & 14 & $e_{7}, e_{8}, e_{10}, e_{4}, e_{5}, e_{6}, e_{9}, e_{11}, e_{12}, e_{18}$ \\
2011 & 13 & $e_{7}, e_{8}, e_{10}, e_{15}$ & \\
2012 & 12 & $e_{8}, e_{10}, e_{15}$ & \\
2013 & 12 & $e_{8}, e_{10}, e_{15}$ & \\
2014 & 12 & $e_{8}, e_{10}, e_{15}$ & \\
2015 & 10 & $e_{8}$ & \\
\hline
\end{tabular}

Source: own.

\section{Data and methodology}

Shadow economy (SE) is the dependent variable analyzed in this paper and the independent variables are of a socioeconomic type (government effectiveness, rule of law, democracy, corruption, GDP per capita, tax revenue, unemployment and urban population) together with variables associated with national cultural dimensions, including some of those in the Hofstede theory (power distance, individualism, masculinity, and uncertainty avoidance).

\subsection{Data}

The variable analyzed is shadow economy (expressed as a percentage of the GDP), and it is measured using the estimations made by Schneider and Medina (2017) using multiple indicators, multiple causes (MIMIC) modeling (see Herwartz et al., 2015; Tafenau et al., 2010; Schneider et al., 2010 and Schneider, 2007). The estimations provided correspond to a database of 158 countries for the 1999-2015. Figure 1 shows the values reached during this period.

The average size of the shadow economies of the 158 countries during the period studied stands at a very notable $31.1 \%$ of the GDP. The geographical distribution of shadow economy also follows a pattern in which there is a certain tendency towards grouping of countries with similar levels. Countries with high levels of shadow economy have neighboring countries with like levels and the same applies for countries with medium and low levels respectively. 


\section{Figure 1}

\section{SHADOW ECONOMY IN WORLD}
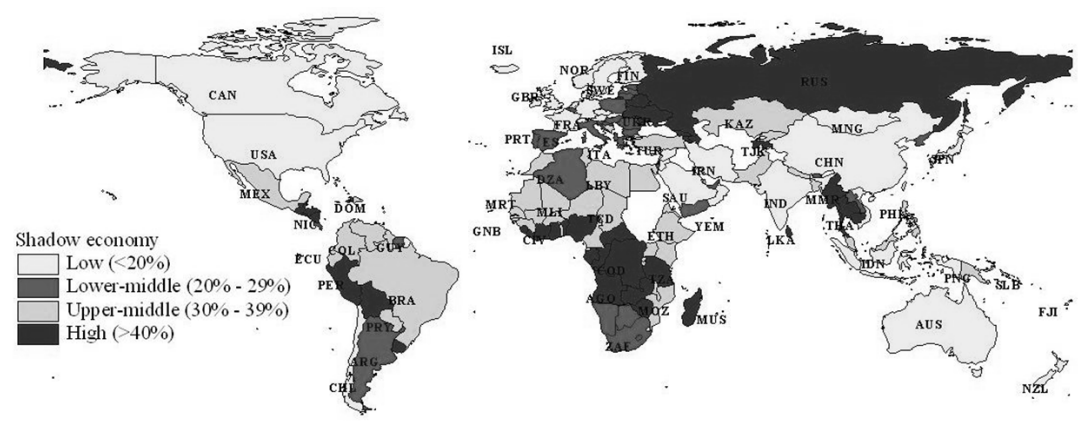

Source: own with data from Schneider and Medina (2017).

\subsection{Dependent variable}

The dependent variable in this study is shadow economy (SE), estimated by Schneider and Medina (2017). In order to fit the sample of the countries in that study to the information available about the explanatory variables used, it has to be adjusted to 82 of the 158 possible countries. Hence, the dependent variable (shadow economy) that we use here is referred to the sample of data from 82 countries $^{5}$, for the period 1999 to 2015.

\subsection{Independent variables}

The explanatory variables that have been taken into account in the estimation developed in this study are:

- PD: Power distance: this refers to the acceptance of hierarchical order and unequal power distribution in institutions and organizations.

- IND: Individualism: this characterizes the level people focus on themselves rather on the group to which belong.

- MASC: Masculinity: this is related to the attitudes about competition and achieving material success.

- UA': Uncertainty avoidance: this is defined as "the extent to which members of a culture feel threatened by uncertainty or unknown situations".

- GOVEF: Government effectiveness: an index (ranging from -2.5 to 2.5) that measures the quality of the public services and the civil service.

- RULE$^{7}$ : Rule of law: this is a measure (ranging from -2.5 to 2.5) of the degree of agent's confidence in and compliance with the rules of society.

- DEMO ${ }^{8}$ : Democracy: an index that measures the degree of democracy. It ranges from 0 to 10 with higher values indicating a higher level of democracy. 
- CORRUP 9 : The perceived corruption index is a composite index that measures the levels of perceived corruption in the public sector in a specific country, using a scale from zero (very corrupted) to ten (absence of corruption) and based on surveys conducted with experts and companies.

- GDPpc: Gross domestic product converted to international dollars using purchasing power parity rates (constant 2011 international \$).

- TAXREV: Tax revenue (\% of GDP): is defined as mandatory transfers to the central government for public purposes.

- UNEMP: Percentage of unemployed population compared to the labour force.

- UP ${ }^{10}$ : Percentage of people living in urban areas.

- LEGALORIGIN: Set of dummies on legal origins of the countries which identify the origin of the Company Law or Commercial Code in each country ${ }^{11}$. They are British legal origin (LEBR), French legal origin (LEFR), Socialist legal origin (LESO), German legal origin (LEGE), and Scandinavian legal origin (LESC). The last one is excluded as a base category.

Table 2 shows the statistical summary of the variables and Table 3 summarizes the correlations between the variables.

Table 2

STATISTICAL SUMMARY OF THE VARIABLES

\begin{tabular}{lcccc}
\hline \multicolumn{1}{c}{ Variable } & Mean & Standard deviation & Minimum & Maximum \\
\hline Shadow economy (SE) & 27.67 & 11.30 & 7.96 & 60.60 \\
Power distance (PD) & 63.85 & 21.14 & 11.00 & 100.00 \\
Individualism (IND) & 40.56 & 21.87 & 6.00 & 91.00 \\
Masculinity (MASC) & 46.91 & 18.18 & 5.00 & 100.00 \\
Uncertainty avoidance (UA) & 65.96 & 20.20 & 23.00 & 100.00 \\
Government effectiveness (GOVEF) & 0.30 & 0.93 & -1.69 & 2.35 \\
Rule of law (RULE) & 0.20 & 0.98 & -2.03 & 2.10 \\
Democracy (DEMO) & 6.54 & 3.61 & 0.00 & 10.00 \\
Perceived corruption (CORRUP) & 4.67 & 2.18 & 0.40 & 10.00 \\
Income per capita (GDPpc) & 20,980 & 19,261 & 562 & 10,263 \\
Unemployment rate (UNEMP) & 8.45 & 5.36 & 0.50 & 27.50 \\
Urban people (UP) & 62.72 & 21.08 & 12.90 & 100.00 \\
Tax revenue (TAXREV) & 16.77 & 6.62 & 0.10 & 36.50 \\
British Legal (LEBR) & 0.26 & 0.44 & 1.00 & 0.00 \\
French Legal (LEFR) & 0.43 & 0.50 & 1.00 & 0.00 \\
Socialist Legal (LESO) & 0.18 & 0.39 & 1.00 & 0.00 \\
German Legal (LEGE) & 0.10 & 0.30 & 1.00 & 0.00 \\
Scandinavian Legal (LESC) & 0.04 & 0.19 & 1.00 & 0.00 \\
\hline S & & & & \\
\hline
\end{tabular}

Source: own with data from Schneider and Medina (2017), Hofstede (1980), The World Bank. Worldwide Governance Indicators Project, Center for Systemic Peace, Transparency International., GDN Growth Database and databank.worldbank.org. 







\subsection{Exploratory analysis of the spatial distribution of shadow economy}

One initial characteristic of the territorial distribution of shadow economy in the world ${ }^{12}$ is, according to the data from the estimations of Schneider and Medina (2017) for the period 1999-2015, its high dispersion. The lowest value recorded was in Switzerland (8.764\%), while the highest was in Georgia, with $63.7 \%$ of the GDP. However, when taking all the observations of the sample into consideration by calculating the standard deviation, which was 0.118 , one concludes that there is notable dispersion, although less intense than that of the variable in question.

Figure 1 shows that the highest levels of shadow economy are to be found in Georgia, Zimbabwe, Bolivia, Gabon, Haiti, Nigeria, Benin, Guatemala, Tanzania, Thailand, Peru, Azerbaijan, Myanmar, Congo, Honduras, Belize, Gambia, Sri Lanka, El Salvador, Côte d'Ivoire, Uruguay, Cambodia, Ukraine, Madagascar, Moldova, Liberia, Central African Republic, Zambia, Nicaragua, Tajikistan, Belarus, Ghana, Angola, Armenia, Sierra Leone and Russian Federation, with values of over $40 \%$. In contrast, the lowest levels are found in Switzerland, United States, Austria, China, Luxembourg, Japan, Singapore, New Zealand, United Kingdom, Australia, Netherlands, Vietnam, Hong Kong and Germany, where the values were below $15 \%$.

Another feature of the distribution of shadow economy is that it adheres to a normal distribution according to the p-value obtained from the Jarque-Bera statistic, 0.444, which means that the assumptions of normality are not rejected.

However, the above results do not take into account the location of each country and the importance of the spatial effect on the dispersion of shadow economy cannot be evaluated.

Figure 2

\section{MORAN'S DISPERSION DIAGRAM OF SHADOW ECONOMY}

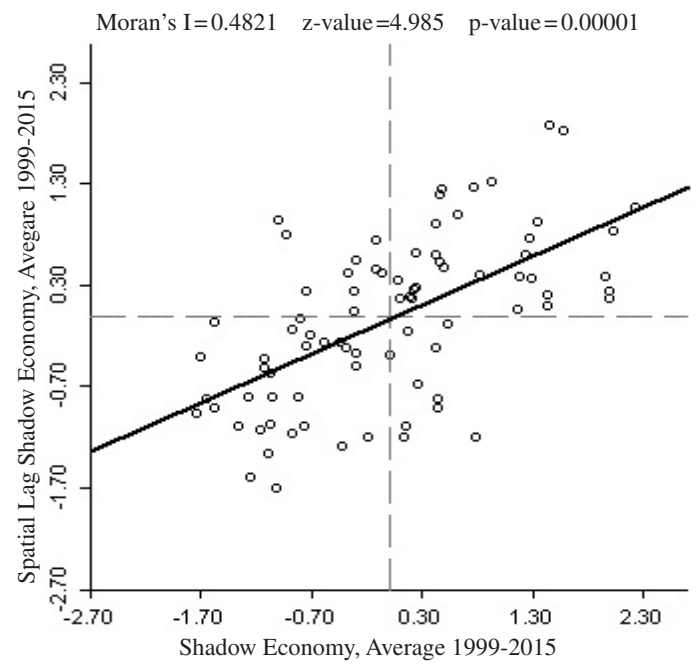

Source: own with data from Schneider and Medina (2017). 


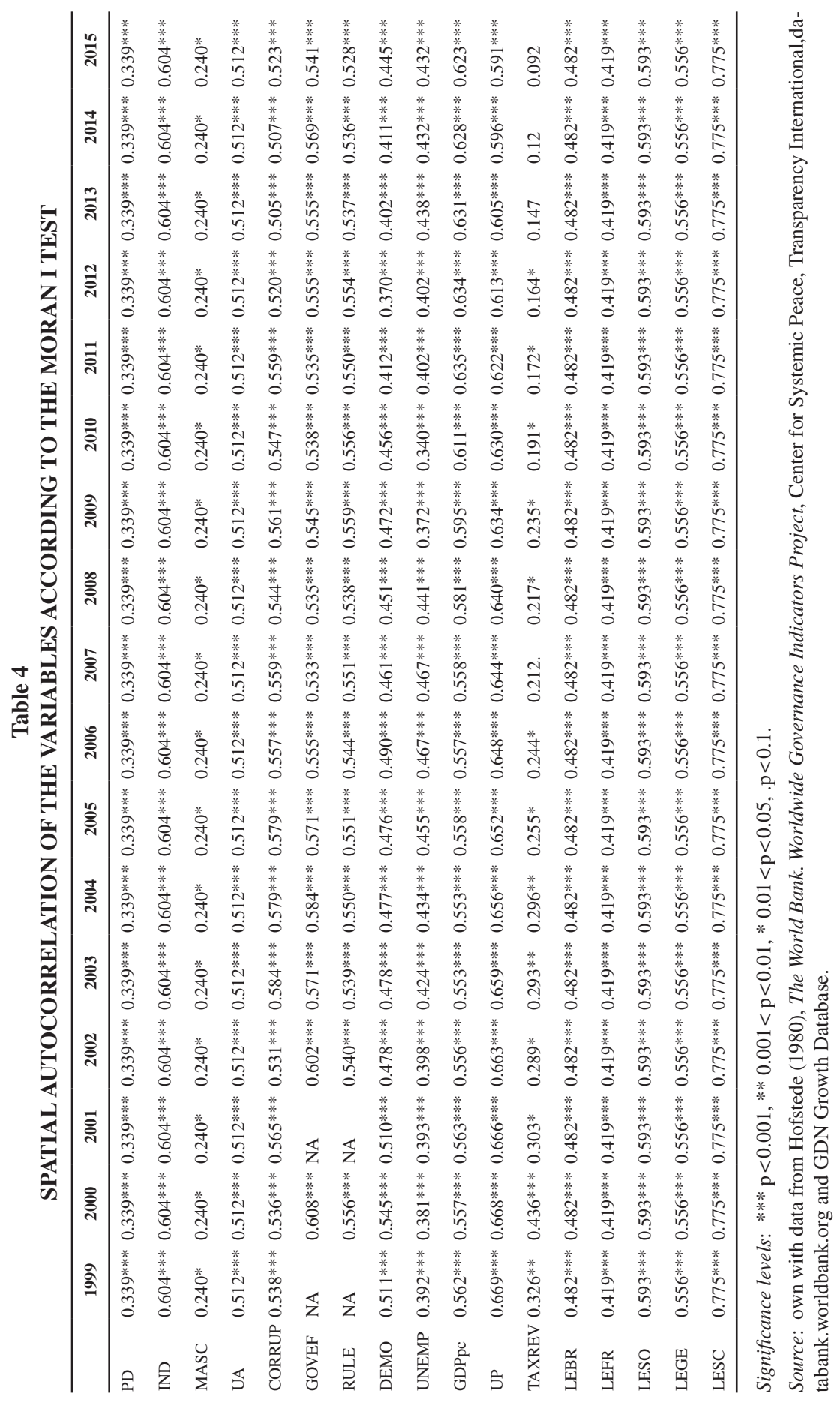


In order to discover the spatial association format ${ }^{13}$ of the distribution of shadow economy we draw in the dispersion diagram of Moran, in which the normalized values of the shadow economy of each country are represented on the $\mathrm{X}$ axis and that of the neighboring countries (spatial lag) on the $\mathrm{Y}$ axis. The intensity of the spatial dependence is obtained using one of the most widely known statistics: Moran's 1 statistic. As stated earlier, the weights matrix $\mathrm{W}$ used in this work has been obtained by using the queen criterion of contiguity.

Figure 2 shows the Moran dispersion diagram and the value of the Moran 1 statistic of the shadow economy variable. It is seen that most of the countries lie in quadrants I and III, indicating that countries with high values of shadow economy have neighbors with similar values and the those with low values have neighbors of like values.

It thus emerges that there is a spatial pattern of positive dependence, which is proved by a MI value that is significant. Therefore, the exploratory spatial analysis shows that the distribution of shadow economy across world countries is marked by a strong spatial dependence.

Consequently, it is essential to consider geographical proximity (spatial correlation) as one of the reasons explaining the observed differences across countries regarding shadow economy together with other socio-economic factors and national culture .

When the exploratory analysis is extended to the explanatory variables (Table 4), the positive spatial autocorrelation in all the variables becomes apparent. As is observed, the intensity of the dependence is especially high in the majority of cultural and socioeconomic explanatory variables, with values of over 0.4 . These results underline the need for spatial filtering that captures the spatial dependence of the explanatory model of the shadow economy.

\subsection{Methodology, the spatial filtering of shadow economy}

We estimate panel regressions of a set of potential determinants of shadow economy for 82 countries over the period from 1999 to 2015 both included. As a robustness check, we employ different model specifications. Model 1 includes only the socioeconomic variables mentioned above (tax revenue, government effectiveness, rule of law, democracy, corruption, GDP per capita, unemployment, legal system and urban population). The specification of this model is:

$$
y_{i t}=\propto+\sum_{k=1}^{12} \gamma_{k} x_{k i t}+\varepsilon_{i t}
$$

where $y_{i t}$ is the dependent variable, $x_{k i t}$ denotes the socio-economic variables above mentioned, $k=1,2, \ldots ., 12, i$ is the country index, $t$ is the year index and $\alpha, \beta_{j}$ and $\gamma_{k}$ are constants.

Model 2 is obtained by adding to model 1 the Hofstede cultural variables, therefore we obtain the expression

$$
y_{i t}=\alpha+\sum_{k=1}^{16} \gamma_{k} x_{k i t}+\varepsilon_{i t}
$$

where $x_{k i t}$ denotes the set of the socio-economic variables and the cultural variables $k=1,2, \ldots ., 16$. 
Finally, model 3 extends model 2 by adding the spatial filter. With the inclusion of spatial filter components (eigenvectors selected for the entire period), Equation (2) becomes:

$$
y_{i t}=\propto+\sum_{k=1}^{16} \gamma_{k} x_{k i t}+\sum_{j \in J} \beta_{j} e_{j i}
$$

where $e_{j}$ is the jth eigenvector, $j \in J=\{1,2,4,5,6,9,11,12,18\}$.

We consider that the tax revenue could be endogenous. Therefore, we address this issue by using the Hausman-Taylor estimator. ${ }^{15}$

Table 5 sums up the outcomes of the estimates of models 1 to 3 .

\section{Results and Discussion}

Table 5 shows the main results of estimating the different regressions with alternative specifications in $\mathrm{Eq}(1)$.

Models 1 and 2 are non-spatial estimations. Model 1 includes socioeconomic variables as independent variables (GDPpc, tax revenue, rule of law, unemployment rates, urban rate, democracy, corruption and legal system). As seen, the impact of socioeconomic variables on the shadow economy is quite robust since differences among coefficients across the models are very small. The coefficients of these variables have the expected sign and are statistically significant, with the exception of government effectiveness and democracy.

The level of shadow economy is positively related to levels of unemployment, so more shadow economy is present in countries that have more unemployment.

On the contrary, shadow economy is negatively correlated with urban population, tax revenue, gross domestic product and rule law. Therefore, in countries with greater agglomeration economies there are lower levels of shadow economy. Also, the tax revenue is greater in countries characterized by lower levels of shadow economy (as found in Mazhar and Méon, 2017). Likewise, higher level of economic development is linked to lower levels of shadow economy in all countries. As well, the higher levels of perceived corruption are, the lower the levels of shadow economy are. Finally, in countries where there is more confidence in the functioning of the rule of law, the levels of shadow economy are lower.

The second column gives estimates of Eq (2), Model 2, which includes Hofstede's variables and socioeconomic variables as independent variables (as in Tsakumis et al., 2007). Unlike the results found in the aforementioned work, we find that only three of the primary variables of interest are statistically significant: individualism (IND), uncertainty avoidance (UA) and masculinity (MASC). The coefficients of uncertainty avoidance and masculinity have the expected sign and are statistically significant. However, we find a positive relation between individualism and shadow economy. The estimated coefficients of socioeconomic variables are similar to those in column 1 . The level of shadow econo- 
my is positively related to levels of uncertainty, so high values of this variable reflect that citizens tend toward more risky behaviors on account of a lack of confidence in their institutions and the rigidness of the legal system, which fosters greater non compliance. Hence, countries with higher UA tend to be more tolerant of corrupt activities and so the level of shadow economy is higher.

In terms of the MASC dimension, a significant and negative relation is found with the levels of shadow economy between countries. Countries with a prevailing masculinity role, MASC, linked to values of competition, performance and achievement, are more aware of their fiscal obligations and have lower levels of shadow economy.

Thus, we conclude that higher UA is related to higher shadow economy levels and higher levels of MASC is related to lower shadow economy levels across countries. However, it is not possible to identify a statistically significant relation between the PD variable with the level of shadow economy.

Thus, the results suggest that three of Hofstede's cultural dimensions (UA, IND and MASC), urban population (UP), unemployment (UNEMP), tax revenue (TAXREV), index of corruption (CORRUP), the level of economic development (GDPpc) and rule of law (RULE) are the main explanatory variables of levels of shadow economy.

These results are intuitive and are in the same line as other findings reported previously in Tsakumis et al.(2007), Dreher and Schneider (2010) and Goel and Saunoris (2014).

Nonetheless, the previous results show a certain bias due to the presence of spatial autocorrelation of the variables. We, therefore, use the spatial filtering model to capture spatial dependence and obtain more robust estimates.

The regression model 3 includes a spatial filter to capture the spatial autocorrelation observed in the dependent variable. This model extends model 2 by adding a spatial filter.

When the research addresses the hypothesis of spatial dependence, the explanatory factors of the shadow economy from a perspective ${ }^{16}$ of cultural and socioeconomic characteristics in the countries of the sample are, the spatial filter, the urban population, unemployment, tax revenue, index of corruption, the rule of law, the level of economic development, the masculinity and uncertainty avoidance.

As shown in table 5, model 3 (which includes Hofstede's, socioeconomic and spatial filter explanatory variables) confirms that of all the Hofstede variables only UA, IND and MASC are explanatory of the level of shadow economy. Likewise, we highlight the importance of spatial dependence to explain the levels of shadow economy across countries. The results of estimating model 3 show that spatial dependence is a significant factor in explaining levels of international shadow economy. They also indicate that only three of Hofstede's cultural dimensions (UA, IND and MASC) are related to the levels of shadow economy across countries. It is also found that economic development levels and the rule of law show a negative and significant relation with levels of shadow economy across countries. 
Table 5

ESTIMATED COEFFICIENTS OF MODELS WITHOUT AND WITH SPATIAL DEPENDENCE

\begin{tabular}{|c|c|c|c|}
\hline \multirow{2}{*}{ Variables } & \multicolumn{2}{|c|}{ Non spatial model } & Spatial Filter model \\
\hline & 1 & 2 & 3 \\
\hline Const & $89.986 * * *$ & $58.931 * * *$ & $65.247 * * *$ \\
\hline UP & $-0.3912 * * *$ & $-0.3947 * * *$ & $-0.3969 * * *$ \\
\hline UNEMP & $0.2739 * * *$ & $0.2684 * * *$ & $0.2670 * * *$ \\
\hline TAXREV & $-0.2836 * * *$ & $-0.2931 * * *$ & $-0.2932 * * *$ \\
\hline GDPpc & $-0.0004 * * *$ & $-0.0004 * * *$ & $-0.0004 * * *$ \\
\hline RULE & $-2.8261 * * *$ & $-3.0470 * * *$ & $-3.0916 * * *$ \\
\hline GOVEF & $-1.6637 * * *$ & $-1.7199 * * *$ & $-1.7422 * * *$ \\
\hline DEMO & -0.0019 & -0.0151 & -0.017 \\
\hline CORRU & $-0.7834 * * *$ & $-0.7906 * * *$ & $-0.7885 * * *$ \\
\hline $\mathrm{PD}$ & & -0.1022 & -0.0822 \\
\hline IND & & $0.3184 * * *$ & $0.3854 * *$ \\
\hline MASC & & $-0.1898 *$ & $-0.2012 *$ \\
\hline UA & & $0.3177 * * *$ & $0.3491 * * *$ \\
\hline LEBR & $-28.487 * *$ & -12.972 & -22.211 \\
\hline LEFR & -20.045 & -11.173 & -21.927 \\
\hline LESO & $-27.102 *$ & $-18.882 *$ & $-25.787 *$ \\
\hline LEGE & -20.520 & -12.982 & -22.740 \\
\hline$e_{1}$ & - & - & 14.743 \\
\hline$e_{2}$ & - & - & 10.239 \\
\hline$e_{4}$ & - & - & -6.6653 \\
\hline$e_{5}$ & - & - & 9.3840 \\
\hline$e_{6}$ & - & - & -18.105 \\
\hline$e_{9}$ & - & - & 20.108 \\
\hline$e_{11}$ & - & - & 1.7761 \\
\hline$e_{12}$ & - & - & -26.590 \\
\hline$e_{18}$ & - & - & 17.021 \\
\hline F-stat & 3044.59 & 2269.21 & 1437.75 \\
\hline p-value & 0.000 & 0.000 & 0.000 \\
\hline Obs. & 974 & 974 & 974 \\
\hline
\end{tabular}

Significance levels: $* * * \mathrm{p}<0.001, * * 0.001<\mathrm{p}<0.01, * 0.01<\mathrm{p}<0.05, . \mathrm{p}<0.1$.

Source: own with data from Source: own with data from Hofstede (1980), The World Bank. Worldwide Governance Indicators Project, Center for Systemic Peace, Transparency International, databank.worldbank.org and GDN Growth Database.

\section{Conclusions}

This paper examines the effects of Hofstede's cultural variables together with other socioeconomic factors on the shadow economy levels across 82 countries in the period 19992015. Our study extends the temporal and country sample and incorporates other independent variables (socioeconomic variables and spatial filter) as significant factors in explaining the levels of shadow economy. Since the distribution of the shadow economy values shows high 
dispersion and strong spatial correlation, the estimation was made with a panel model that incorporates the spatial filtering technique and it confirmed that under conditions of spatial dependence the levels of shadow economy in the countries are related to three of Hofstede's cultural dimensions (uncertainty avoidance, individualism and masculinity), confidence in the rules of law, levels of economic development, urban population, perceived corruption, tax revenue and unemployment. Specifically, the results indicate the level of shadow economy is positively related to levels of uncertainty, so high values of this variable reflect that citizens tend toward more risky behaviors on account of a lack of confidence in their institutions and the rigidness of the legal system, so fosterings greater non compliance. Hence, countries with higher uncertainty tend to be more tolerant of corrupt activities and so the level of shadow economy is higher. In terms of the masculinity dimension, a significant and negative relation is found with the levels of shadow economy between countries. Countries with a prevailing masculinity role, linked to values of competition, performance and achievement, are more aware of their fiscal obligations and have lower levels of shadow economy. It is also obtained that the Gross Domestic Product per capita coefficient is negative and significant, suggesting that countries with higher levels of economic development register lower levels of shadow economy. Greater development is associated with more control of illegal activities and the opportunity cost of infringement is higher, meaning shadow economy is less attractive. These results are in line with Doupnik and Tsakumis (2004) and Tsakumis et al. (2007), Dreher and Schneider (2010), Buehn and Schneider (2012), and Goel and Saunoris (2014).

The results also support the importance of unemployment, urban population, tax revenue and corruption on shadow economy. Shadow economy is positively related to unemployment and negatively correlated with urban population, tax revenue and perceived corruption index.

Lastly, we also found that higher (lower) rule of law is associated with lower (higher) shadow economy. Therefore, in countries where there is more confidence in the functioning of the rule of law, the levels of shadow economy are lower.

Our results indicate that there is interaction of the shadow economy between neighboring countries, so low/high levels of shadow economy at home are associated with low/high levels of shadow economy in a neighboring country. Therefore, policymakers should establish coordinated social awareness measures in the supranational policies (e.g. social stigmatization programs), since behavior of individuals from neighboring countries affects the behavior of individuals in the country.

The results point to the existence of a pattern of countries with higher levels of shadow economy, characterized by low levels of rule of law efficiency, high uncertainty avoidance, low role of masculinity, high individualism, high unemployment rate, high corruption, low urban population, low tax revenue and low economic development levels. This profile characterization may be useful to policymakers in that it can help to direct measures used to reduce the high prevalence of shadow economy.

In summary, our findings justify the importance of including the cultural dimension and its spatial interrelations into any strategy used to fight shadow economy. 


\section{Notes}

1. See Cliff and Ord (1981): 246.

2. These models can be found in Anselin (1988), Anselin (2001), Anselin and Hudak (1992) and LeSage and Pace (2009), among others.

3. Griffith's method $(1996,2000)$ has been used successfully in the field of economics: in the analysis of unemployment rates in a spatial context (see Kosfeld and Dreger, 2006; Patuelli et al. 2011) and economic growth (Cravo and Resende, 2013).

4. We chose those eigenvectors whose Moran I value (MI) fulfilled that MI/max(MI) is greater than or equal to 0.25 (see Griffith, 2003).

5. Albania, Angola, Argentina, Armenia, Austria, Azerbaijan, Bangladesh, Belgium, Bhutan, Brazil, Bulgaria, Burkina F., Byelarus, Canada, Chile, China, Colombia, Croatia, Czech R., Denmark, Ecuador, Egypt, El Salvador, Estonia, Ethiopia, Finland, France, Germany, Ghana, Greece, Guatemala, Honduras, Hungary, India, Indonesia, Iran, Ireland, Israel, Italy, Jordan, Kenya, Kuwait, Latvia, Lebanon, Libya, Lithuania, Luxembourg, Malawi, Malaysia, Mexico, Morocco, Mozambique, Namibia, Nepal, Netherlands, Norway, Pakistan, Peru, Poland, Portugal, Romania, Russia, Saudi Arabia, Slovakia, Slovenia, South Africa, Spain, Suriname, Sweden, Switzerland, Syria, Tanzania U.R, Thailand, Turkey, Ukraine, U. Arab E., U. Kingdom, United States, Uruguay, Venezuela, Vietnam, Zambia.

6. The definitions of UA, IND, PD and MASC are from Hofstede (1980) and are available at www.geerthofstede. nl. Only these four dimensions have been used because they were available for all the countries studied.

7. The data of RULE and GOVEF come from The World Bank. Worldwide Governance Indicators Project. Available from http://info.worldbank.org/governance/wgi/index.aspx\#home.

8. The data come from Center for Systemic Peace, available from http://www.systemicpeace.org/inscrdata.html.

9. The values for the CORRUP variable come from Transparency International.

10 The data of GDPpc, UNEMP, TAXREV and UP come from the World Bank database: http://databank.worldbank.org.

11. They are extracted from Global Development Network Growth Database. Available from: https://www.sscnet. ucla.edu/polisci/faculty/treisman/Papers/what_have_we_learned_data.xls.

12. For the 82 countries selected.

13. For more details of the perspectives and techniques of exploratory analysis of spatial data, see Anselin (1988).

14. We employed Hofstede's cultural framework.

15. Similar results can be obtained when conducting estimations employing instrumental variables. Details are available upon request.

16. Most research seeks to explain the levels of tax non compliance from the focus of characteristics of individuals linked to various psychosocial, demographic, economic, and cultural factors associated with the principles and values of each person. Here we research how surrounding cultural, national and socioeconomic factors affect aggregate values of shadow economy.

\section{References}

Alarcón, G., Buendía, J. D. and Sánchez, M. M. (2016), "El rechazo al fraude fiscal en España: antes y después de la gran crisis", Hacienda Pública Española/Review of Public Economics, 218-(3/2016): 33-56.

An, D. and Kim, S. (2007), "Relating Hofstede's masculinity dimension to gender role portrayals in advertising: A cross-cultural comparison of web advertisements", International Marketing Review, 24(2): 181-207. 
Anselin, L. (1988), Spatial econometrics: Methods and models, Dordrecht, Kluwer Academic Publishers.

Anselin, L. (2001), "Spatial econometrics", in: Baltagi, B. H. (Eds.), A companion to theoretical econometrics, Malden, Blackwell, 310-330.

Anselin, L. and Hudak, S. (1992), "Spatial econometrics in practice: A Review of software options", Regional Science and Urban Economics, 223: 509-536.

Arrazola, M. and Mauleón, I. (2011), "La economía sumergida en España”, in: Dos ensayos de actualidad sobre la Economía Española. La Economía Sumergida en España, Madrid, Funcas, 13-77.

Buehn, A. and Schneider, F. (2012), "Corruption and the shadow economy: like oil and vinegar, like water and fire?", International Tax and Public Finance, 19: 172-194.

Center for Systemic Peace, http://www.systemicpeace.org.

Cliff, A. D. and Ord, J. K. (1981), Spatial Process: Models \& Applications, London: Pion.

Cravo, T. A. and Resende, G. M. (2013), "Economic growth in Brazil: a spatial filtering approach", The Annals of Regional Science, 50(2): 555-575.

De Juan, A. (1995), "Manifestaciones del comportamiento fraudulento en España. Análisis de causas y de estrategias preventivo-correctoras", Información Comercial Española, ICE: Revista de Economía, 741: 55-65.

De Mooij, M. (2004), Consumer behavior and culture: Consequences for global marketing and advertising, Thousand Oaks, CA: Sage.

De Mooij, M. and Hofstede, G. (2002), "Convergence and divergence in consumer behavior: implications for international retailing", Journal of retailing, 78(1): 61-69.

De Mooij, M. and Hofstede, G. (2010), "The Hofstede model: Applications to global branding and advertising strategy and research", International Journal of Advertising, 29(1): 85-110.

Doupnik, T. S. and Tsakumis, G. T. (2004), "The influence of conservatism and secrecy on the interpretation of tests of Gray's theory of cultural relevance and suggestions for future research", Journal of Accounting Literature, 23: 1-48.

Dreher, A. and Schneider, F. (2010), "Corruption and the shadow economy: an empirical analysis", Public Choice, 144, 215-238.

Franke, R. H., Hofstede, G. and Bond, M. H. (1991), "Cultural roots of economic performance: A research note", Strategic Management Journal, 12(S1): 165-173.

Frey, B. S. and Schneider, F. (2015), "Informal and Underground Economy", in: J. D. Wright (Ed.), International Encyclopedia of the Social and Behavioral Sciences (2nd ed.), Elsevier Ltd, 12: 50-55.

Goel, R. K. and Saunoris, J. W. (2014), "Global corruption and the shadow economy: spatial aspects", Public Choice, 161: 119-139.

Griffith, D. A. (1996), "Spatial autocorrelation and eigenfunctions of the geographic weights matrix accompanying geo-referenced data", The Canadian Geographer, 40: 351-367.

Griffith, D. A. (2000), "A linear regression solution to the spatial autocorrelation problem”, Journal of Geographical Systems, 2: 141-156.

Griffith, D. A. (2003), Spatial autocorrelation and spatial filtering: gaining understanding through theory and scientific visualization, Springer-Verlag, Berlin. 
Hassan, M. and Schneider, F. (2016), "Size and Development of the Shadow Economies of 157 Countries Worldwide: Updated and New Measures from 1999 to 2013", IZA Discussion Paper, 10281.

Hermeking, M. (2005), “Culture and Internet consumption: contributions from cross-cultural marketing and advertising research", Journal of Computer-Mediated Communication, 11(1): 192-216.

Herwartz, H., Tafenau, E. and Schneider, F. (2015), "One Share Fits All? Regional Variations in the Extent of the Shadow Economy in Europe", Regional Studies, 49(9): 1575-1587.

Hofstede, G. (1984), "Cultural dimensions in management and planning", Asia Pacific Journal of Management, 1(2): 81-99.

Hofstede, G. (1980), Culture's consequences: International differences in work-related values, London, Sage Publications.

Hofstede, G. (1986), "Cultural differences in teaching and learning”, International Journal of Intercultural Relations, 10(3): 301-320.

Hofstede, G. (1991), Cultures and Organizations: Software of the Mind, London, McGraw-Hill.

Hofstede, G. (1993), "Cultural constraints in management theories", Academy of Management Perspectives, 7(1): 81-94.

Hofstede, G. (1994), “Management scientists are human”, Management Science, 40(1): 4-13.

Johnson, J. P. and Lenartowicz, T. (1998), "Culture, freedom and economic growth: do cultural values explain economic growth?”, Journal of World Business, 33(4): 332-356.

Kogut, B. and Singh, H. (1988), "The effect of national culture on the choice of entry mode", Journal of International Business Studies, 19(3): 411-432.

Kosfeld, R. and Dreger, C. (2006), "Thresholds for employment and unemployment: A spatial analysis of German regional labour markets, 1992-2000”, Papers in Regional Science, 85(4): 523-542.

LeSage, J. P. and Pace, R. K. (2009), Introduction to Spatial Econometrics, Boca Raton, CRC Press Inc.

Mazhar, U. and Méon, P. G. (2017), “Taxing the unobservable: The impact of the shadow economy on inflation and taxation", World Development, 90:89-103.

Molero, J. C. and Pujol, F. (2012), “Walking Inside the Potential Tax Evader's Mind: Tax Morale Does Matter", Journal of Business Ethics, 105(2): 151-162.

Patuelli, R., Griffith, D. A., Tiefelsdorf, M. and Nijkamp, P. (2011), "Spatial filtering and eigenvector stability: space-time models for German unemployment data", International Regional Science Review, 342: 253-280.

Sardá, J. (2014), La Economía Sumergida pasa factura. El avance del fraude en España durante la crisis, Ministerio de Hacienda, España.

Schneider, F. (2004), "The Size of the Shadow Economies of 145 Countries all over the World: First Results over the Period 1999 to 2003”, IZA Discussion Paper, 143. Bonn, Institute for the Study of Labor (IZA).

Schneider, F. (2007), "Shadow Economies and Corruption all over the World: new estimates for 145 countries", Economics, The Open-Access, Open-Assessment E-Journal, 1(2007-9): 1-66.

Schneider, F., Buenh, A. and Montenegro, C. E. (2010), "Shadow economies all over the world: New Estimates for 162 Countries from 1999 to 2007”, World Bank Policy Research. Working Paper, 5356. 
Schneider, F. and Medina, L. (2017), "Shadow Economies around the World: New Results for 158 Countries over 1991-2015", Johannes Kepler University of Linz Department of Economics, Working Paper, 1710, July 2017, http://www.econ.jku.at/papers/2017/wp1710.pdf.

Smith, A. and Hume, E. C. (2005), "A Comparison and Ethics: of Accountants' Ethical Belief Power Systems in the Individualism/Collectivism and Power Distance Contexts", Journal of Business Ethics, 62(3): 209-220.

Steenkamp, Jan-Benedict E. M., Hofstede G. and Wedel, M. (1999), "A Cross-National Investigation into the Individual and National Cultural Antecedents of Consumer Innovativeness", Journal of Marketing, 63(2): 55-69.

Tafenau, E., Herwartz, H. and Schneider, F. (2010), "Regional Estimates of the Shadow Economy in Europe", International Economic Journal, 24(4): 629-636.

The World Bank. Worldwide Governance Indicators Project. Washington. Data available from http:// info.worldbank.org/governance/wgi/index.aspx\#home.

Tiefelsdorf, M., Griffith, D. A. and Boots, B. (1999), "A variance-stabilizing coding scheme for spatial link matrices", Environment and Planning A, 31: 165-180.

Torgler, B. (2001), "Is Tax Evasion Never Justifiable?", Journal of Public Finance and Public Choice, 19: $143-168$.

Torgler, B. (2005), “Tax Morale in Latin America”, Public Choice, 122: 133-157.

Torgler, B. and Schneider, F. (2009), "The Impact of Tax Morale and Institutional Quality on the Shadow Economy", Journal of Economic Psychology, 30, 228-245.

Torgler, B., Schneider, F. and Schaltegger, C. A. (2010), "Local Autonomy, Tax Morale, and the Shadow Economy”, Public Choice, 144(1): 293-321.

Transparency International Corruption Perception Index, [http://www.transparency.org/research/cpi/ overview].

Tsakumis, G. T., Curatola, A. P. and Porcano, T. M. (2007), "The relation between national cultural dimensions and tax evasion", Journal of International Accounting, Auditing and Taxation, 16: 131-147.

World Bank. Global Development Network Growth Database, [http://econ.worldbank.org/].

World Bank. World Development Indicators. DataBank.

\section{Resumen}

El objetivo de este trabajo es contribuir a la evidencia empírica existente acerca de los factores que intervienen en la economía sumergida. Las estimaciones corresponden al período 1999-2015 y 82 países.

Este artículo analiza el efecto de las variables culturales de Hofstede y otros factores socioeconómicos en la economía sumergida, introduciendo la variable espacial como una variable explicativa adicional. Como novedad, nuestra estimación utiliza un modelo de panel que incorpora la técnica del filtrado espacial. Este estudio confirma que la cultura nacional y el desarrollo de un país son factores importantes para explicar los diferentes niveles de la economía sumergida.

Palabras clave: Teoría de Hofstede, economía sumergida, evasión fiscal, cumplimiento tributario, dependencia espacial.

Clasificación JEL: H2, H26, O17, O5. 